\title{
The Most Common Translation Problems Encounter the Saudi Students in Translating Selected Arabic Literary Items and their Point of Views behind these Problems
}

Issam Mostafa Taamneh*

Faculty of Education and Arts, Tabuk University, Saudi Arabia

Corresponding Author: Issam Mostafa Taamneh, E-mail: dr.issamtaamneh@gmail.com

\section{ARTICLE INFO}

Article history

Received: February 18, 2018

Accepted: April 23, 2018

Published: September 01, 2018

Volume: 7 Issue: 5

Advance access: July 2018

Conflicts of interest: None

Funding: None

\begin{abstract}
The current study aimed to investigate the most common translation problems that encountered the Saudi students in translating some of the literary items from Arabic into English. In addition, the study tried to investigate the most difficult terms that the students faced while translating them. Moreover, it aimed to explore the participants' point of views behind such translation problems. To achieve the purpose of the study, a translation test, which involved 20 items and expressions, was prepared in advance. Furthermore, an interview was made to the participants to ask them about their point of views concerning the reasons behind encountering such translation problems. The sample of the study consisted of 15 male fourth year Englishmajored university students, who were chosen purposefully, at the University College of Taymaa in the first semester of the academic year 2017/2018 in Saudi Arabia. The design of the study was a qualitative as well as quantitative method. The data that were obtained from the participants' answers in the translation test as well as the participants' point of views in the interview were analyzed using the appropriate statistical analyses. The findings of the study showed that the students' achievement in translating the items of the terms of address was the best compared with their results in the other two groups (lexical and cultural). Moreover, the analysis of the students' interviews indicated that the lack of practice and lack of translation courses are a main reason in facing such these problems. Based on the findings, the researcher presented some recommendations and suggestions to develop students' translation competence such as increasing the number of the translation courses that are presented to the students in their studying to have more practice in the process of translation. Moreover, more concentration should be given to the lexical, cultural, and terms of address problems in translation. Besides, students must be trained on how to use the bilingual dictionaries in the process of translation to get the intended meaning while rendering from Arabic into English and vice versa.
\end{abstract}

Key words: Translation, Cultural Differences, Style, Source Language (SL), Target Language (TL).

\section{INTRODUCTION}

Translation is a necessary process in this changing world as it helps in transferring meanings, ideas, opinions of people in the world from one language into another one. Moreover, it is important as it helps in transmitting knowledge, science, and technology when specific translation institutions as well as individuals translate such important fields of knowledge from one language into other different languages. Despite its importance in our life, it is expected to have some problems while translation from one language into other languages.

Since translation, as stated above, is an activity that may involve problems including the stylistic ones due to the cultural, and lexical problems, the role of the experienced translator is, therefore, to find these signals and try to translate them adequately. If the translator has this knowledge or experience, this may help him to render the text under trans- lation as effective as the original. Otherwise, he may fail in translating these expressions adequately and naturally.

In fact, any attempt that aims to translate some literary expressions from Arabic into English is said to be not straightforward process, as it needs practice and experience. In fact, we may say that studies have touched upon this field of literary translation is still few and needs a lot of investigation and research. Consequently, the importance of studying translation of some literary terms becomes necessary and important in the field of education.

Because of the different languages spoken by different groups of people in many different areas of this modern world, translation gains more importance in the world day after day. It has been gaining importance and receiving much attention as a means of communication. Catford (1965,p. vii) pointed out that "translation is an activity of enormous importance in the modern world and it is a subject of interest 
not only to linguists, professional and amateur translators and language-teachers, but also to electric engineers and mathematicians." He (Ibid, p. 1) defined translation as an "operation performed on languages: a process of substituting a text in one language for a text in another." Ghazal (2008, p.1), and in the same context, defined it as "all the processes and methods used to render and/or transfer the meaning of the source language text into the target language as closely, completely, and accurately as possible."

The process of translation requires from the translators to do their best to convey and transfer the ideas in the source language text (SLT) into the target language text (TLT) in a complete and correct way otherwise; many translation problems appear and this will definitely lead to a lot of misunderstanding between the SL text and the rendering TL text. In this aspect, Waard and Nida (1986, p. 42) stated that "There is no doubt about the fact that absolute communication in translation is impossible", but they ask the translator to do his best in order to create the closest natural equivalence. Despite the efforts that the translator may do, some loses are expected to occur in meaning, structure, and style due to many reasons.

In the process of translation, the translator is expected to convey the message and the effect of the original text to the target language receiver although it is difficult to achieve an equivalent translation because he is dealing with many language components such as grammar, vocabulary, style, and phonology.

The question that may spring into one's mind is related to the possibility of producing an appropriate translation without much loss of meaning and structure or distortion of the message. In other words, we may ask the following: To what extent is the translator able to render the SL text into an equivalent TL text without a lot of loss or distortion of meaning?

Neubert and Shreve (1992,p. 2) believed that "it is completely wrong for the translator to change the text from its natural surrounding and changing it into a different linguistic and cultural atmosphere, simply because it will lose a lot of its value and effect on the reader or listener's response." The concentration here is mainly on meaning because it refers to complicated related parts of language such as syntax, vocabulary, style, and phonology (Ghazal 2008, p.2).Students of translation are expected to face some of the translation difficulties when they translate cultural and lexical items due to the differences between the two languages culturally and linguistically.

Translation -as we know - is a human activity, which seeks to find the equivalent text in the TL, it is so important for the translator to have a good experience as well as an excellent background about the target language that he is translating to.

\section{LITERATURE REVIEW}

Several studies have been carried out on the notion of cultural and lexical in the process of translation but few of them investigated the problems and the reasons behind facing such problems. Moreover, few studies focused and discussed the difficulties that faced the Saudi students in translating some of the literary texts. One of the reasons behind such problems is the differences regarding the cultural and lexical problems so that students can not find the equivalents for some words when they deal with such cultural and lexical items, as well as the notion of "style", which differs from one translator to another (Crystal 1992, Hartman and Stork 1972). The subject of style has been the subject of endless controversy, and its essence is still debated (see for instance Enkvist, Spencer, and Gregory 1967).

When the translator does not understand the writer's or the author's style and his/her background, it is expected to commit major translation problems due the gap that comes on the surface simply because the translator does not grasp the writer's intention in that literary work.

Ghazal (ibid, p.223) defined style as "the different choices made by writers from the language stock in regard to layout (or shape), grammar, vocabulary (or words) and phonology (or sounds).'This definition indicates that translators must take these components in the process of translation. In doing so they will be able, and to some extent, in rendering the SL text into close, adequate, and acceptable TL texts.

A good example for the notion of style, and how it is relevant to meaning, is what Ghazal (ibid, p.223) mentioned for rendering the following statements:

" a. Her father died yesterday.

b. Her father was killed yesterday.

c. Her father licked the dust yesterday.

d. Her father kicked the bucket yesterday.

e. Her father passed away yesterday.

f. Her father was martyred yesterday.

g. Her father slept his last sleep yesterday.

h. Her father was hanged yesterday."

The reader of the above statements will know that they are expressing on idea that is the death of her father, so rendering them into one clear version (مات و الدها أمس) convey the main message the eight sentences try to convey for the readers or the listeners. If they are translated according to the notion of the difference of style due to the differences in the words they are carrying, then they will be translated as the following:

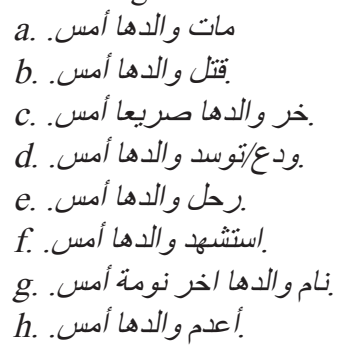

Source: Ghazal (2008).

The differences of the above statements come from the fact that they are stylistically and semantically different from each other as each statement show a different way of her father's way of death, though they are expressing one idea that is "Death".

Tahaineh and Tafish (2011) conducted a study to show whether teaching some translation techniques may help in discovering the problems in order to solve them through the effectiveness of cooperative learning approach in a trans- 
lation classroom. The sample of the study consisted of 43 students who were studying a basic translation course at the school of Languages Studies and Linguistics at the University of Kebangsaan in Malaysia. In the study, both quantitative and qualitative methods were used to analyze the students' respondents to the questionnaire and the translation tasks. The findings of the study showed that the majority of the students were competitive learners. Moreover, the results showed that students preferred to work in small groups (Between 2 to 3 ) rather than the group that consisted of 4 to 5 members. In addition, the results pointed out that the respondents disliked the idea of working in groups, as they preferred discussing with their classmates about the ideas they would to share and talk about.

In another study conducted by Mares (2012) about the cultural difficulties in translation from English into Arabic that faced translators due to the mismatches in beliefs and culture between the Western cultures and the Arab culture, he found that the most problematic aspects that take place in the process of translation are the cultural differences, religious facts, and diglossia. The researcher concluded that translators should be aware of the differences between English and Arabic linguistic systems as they cause problems in the process of rendering. Moreover, the cultural and religious differences between the two languages should be taken into account to create the appropriate close and equivalent translations.

Al-Sohbani and Muthanna (2013) investigated the major challenges that faced Yemeni students when translating from Arabic into English and vice versa. The researchers used the qualitative analyses to classify the most problematic issues in translation. The researchers found that the most problematic translational issues were insufficient lexical knowledge, inadequate knowledge and practice of grammar, inadequate cultural backgrounds, and inappropriate teaching atmosphere. The researchers concluded that there should be re-systematic reforms of the Yemeni curriculum, the pedagogy, and decreasing the number of the students at Yemeni classes.

Dweik and Abu Helwah (2014) conducted a study to investigate the cultural and the linguistic problems that faced Jordanian graduate students in the Middle East University. The sample of the study compromised 20 M.A students during the first academic year 2012/2013. The researchers designed a translation test that consisted six of historical and religious Arabic texts. The results of the study showed that students faced many cultural and linguistic problems such as structural, stylistic, lexical, punctuation errors,and cultural terms. The researchers concluded that these problems resulted from the differences in the linguistic systems between the two languages, lack of awareness to the importance of the context in the process of translation, lack of students' awareness to the cultural differences, and the lack of experience in dealing with dictionaries while translating.

Almubark, Abd.Manan, and Al-Zubaid (2014) studied the hindrances that faced students while translating specific cultural concepts from Arabic into English. The sample of the study consisted of 100 students of both sexes in the final year at Al Imam Al Mahdi University in Sudan who studied at the faculty of English in Sudan. Two instruments were used in this study: A translation test and an open-ended interview. The results of the study showed that the students faced many problems in translation especially the specific cultural concepts when translating from Arabic into English. Moreover, the study pointed that literal translation as well as cultural aspects resulted in these translation problems.

Bakir and Lazim (2015) conducted a study about the stylistic problems encountered the Arab students at the university level at Ajman University of Science and Technology (UAE) in translating from Arabic into English. Thirty advanced-level students were chosen from the Department of English Language and Translation for the study. The students were given a text that talked about Basrah, Iraq. It talked about the city's economic and cultural history. The researchers analyzed the students' translations concerning the text. The findings of the analysis showed that the students faced serious problems in rendering style as they focused on translating the words as separate and isolated items. The results also pointed out the students' errors that appeared in the process of the rendering indicated that the translator should be aware for both linguistic and cultural aspects for any text being translated.

Elachachi (2015) conducted a study to explore the cultural barriers that face the Algerian EFL students' writing due to cultural differences between Arabic-speaking and English-speaking communities. The researcher chose a sample of learners consisted of 16 EFL students from the University of Tlemcen in Algeria. To discover the students' writing difficulties, a contrastive rhetoric was used in this study. The results of the study indicated that the cultural differences related to the linguistic factors such as alphabet, and letters were the main reason for the big amount of mistakes that the students committed in writing their compositions. Moreover, the researcher found that the differences between the two languages in the metaphorical as well as the syntactic styles cause many difficulties for Algerian students' writings.

Jabak, Abdullah, and Mustapha (2016) conducted a study to explore the difficulties of translating collocations from $\mathrm{Ar}$ abic into English that faced the Saudi undergraduate students at the Department of English at Teachers college of King Saud University in the second semester of the academic year 2015.The sample of the study consisted of 50 students. The researchers prepared a quiz that consisted of 15 Arabic sentences that included collocations. The study's findings revealed that the majority of the students could not give equivalent, close, and natural renderings for the colocations because of many reasons such as adopting the literal translations for them, misusing of the dictionaries, and having very little knowledge about the concept of collocation and the best methods to deal with them in the process of translation.

What distinguishes this study from the above studies is that it examines the translation problems in three different categories; cultural, lexical, and terms of address that were taken from one of the literary Arabic novels. Whereas the studies that were mentioned above discussed or studied one or two of the translation problems. Moreover, it tried to 
examine the difficulty of translating these items that faced the Saudi TEFL students from their point of views as they were asked to write freely about these problems. The study tries to show the most difficult sentences that students faced while doing their test and the reasons behind such difficulty.

\section{STATEMENT OF THE PROBLEM}

From the researcher's experience in the field of translation, and while teaching different translation courses, he finds that translation is not an easy task for most of the experienced translators because of many different reasons. The same situation face Arab as well as Saudi EFL students while translating due to many reasons and problems such as cultural, stylistic, and linguistic ones. The researcher and other researchers have noticed that the majority of Arab as well as Saudi EFL students, who study translation courses, face such these difficulties due to the cultural as well as the linguistic gaps between Arabic and English (Al-Sohbani and Muthanna 2013; Dweik and Abu Helwah 2014; Almubark, Abd. Manan; and Al-Zubaid 2014; and Bakir and Lazim 2015).

The researcher, while teaching translation courses and for different academic levels, has noticed that students face a lot of problems when they are set to translate some literary texts, so the researcher hopes to find and discus the reasons behind these problems. This fact is supported by other Arab researchers such as Elachachi 2015, and Jabak, Abdullah, and Mustapha 2016.

In translating texts of different sources, it is expected to find some terms or expressions that are difficult to be translated despite their importance in understanding the whole text and for grasping its content. The researcher believes that clarifying and illustrating these reasons when translating literary works in particular helps the translator to convey the SL text into an accurate close TL text.

\section{PURPOSE AND QUESTIONS OF THE STUDY}

The study aimed to explore the most difficult translation problems that faced the Saudi EFL students in translating selected literary items and expressions from Arabic into English due to lexical, cultural, and terms of address problems. Moreover, it aimed to explore the most difficult sentences that faced students while translating them from Arabic into English among the three groups. Furthermore, it tried to explore the reasons behind such problems from the students' point of views.

The study aimed to answer the following questions:

1. What are the most difficult translation problems that faced the Saudi EFL students in their translation?

2. Which one of the exam's sentences was the most difficult one among the sentences of the three groups?

3. What are the reasons behind facing such translational problems from the students' point of views?

The study is limited due to the following factors:

1. The number of the items and the expressions that were chosen to be translated.Only 15 items were chosen to conduct the study.

2. The limited number of students who participated in translating the items and the expressions of the study.
3. The number of types for the translation problems. Only three types were chosen; the lexical problems, cultural problems, and terms of address problems.

\section{SIGNIFICANCE OF THE STUDY}

The significance of this study comes from the fact that few studies have touched upon the lexical, cultural, and terms of address problems that face Saudi students in translation. Therefore, this study attempts to investigate the most common cultural, lexical, and terms of address problems that faced the Saudi EFL students in translating selected literary items from Arabic into English. Moreover, it aimed to explore the participants' point of views behind such translation problems that may result in the distortion of the meaning. In addition, it may spot the light on the most necessary procedures that the teachers of translation should take to overcome the problems that their students may face when dealing with some literary texts. Furthermore, it is going to present some recommendations for those who work in the field of translation whether they are teachers or students.

\section{METHODOLOGY}

\section{Participants of the Study}

The sample of the test consisted of (15) B.A. students who were studying English language at the University College of Taymaa, one of the five branches for Tabuk University in KSA. The sample of this study was purposefully chosen as they are studying a translation course (Translation 4, ENGL.410) in the first semester of the academic year 2017/2018. All of these students are native speakers of Arabic. They are studying English at Languages and Translation Department at Taymaa College to get their B.A certificates. The subjects have studied during their B.A. program four courses in translation from Arabic into English and vice versa (Translation 1, Translation 2, Translation 3,) as well as a course that is entitled "Basics of Translation" that students study in the first semester of their second academic year. They are expected to have a good command in both Arabic and English.

\section{Instruments of the Study}

To conduct the study, the following instruments were used:

I- The translation test. It consisted of 20 items and expressions that were taken from Mahfouz' novel (The Thief and the Dogs). These items were divided into three types of translation problems:

1. Lexical problems.

2. Cultural problems.

3. Terms of address problems.

The participants were asked to translate only the underlined items. They were given enough time to do so. The researchers, and in order to get what we call the correct and a close rendering, consulted a group of professional translators at Yarmouk University such as professors in translation who 
are working at the Department of Translation at Yarmouk University and have a good experience in translation. Their translations are considered as referees. The researcher provided the translators with the same test that was given to the students and asked them politely to give their appropriate renderings for the phrases and the items that were chosen to conduct the study.

The first part consisted of 10 expressions. The second and the third parts consisted of 10 expressions; five items for each type. The purpose of the translation test was to discover the students' most common translation problems in the three types.

II- The interview. The interview was carried out after applying the translation test for the participants in the study. The purpose behind carrying that interview was to get the students' point of views towards the reasons behind facing such translational problems. The researchers analyzed the participants' responses according to the interview's question.

\section{Validity and reliability of the translation test}

To insure the validity of the translation test, a jury of five specialists in the field of translation in the department of Translation at Yarmouk University, and three of colleagues who hold master and Ph.D. degrees in translation, and work as lecturers in different translation departments in Jordan and Saudi Arabia, were asked politely to participate in the process of validity. Their comments, suggestions and modifications were taken into consideration. To obtain the tests reliability, it was computed on a pilot study consisted of 20 students using the test-retest method. The reliability coefficient was compute using Cronbach's alpha formula and it was.83, which indicate satisfactory reliability value.

\section{PROCEDURES OF THE STUDY}

This study is an analysis of translation problems that faced the Saudi EFL students in translating a specific literary items. The aim of this study is to investigate the most translation problems that faced the students. Moreover, it aims at spotting the light on the reasons behind facing such these problems while translation according to the students' point of views. Therefore, the procedures of this study will consist of the following steps:-

(1) The subjects were asked to translate only the underlined items and phrases that are taken from Mahfouz' novel (The Thief and the Dogs) from Arabic into English. Enough time was given for the students to do the task (Time: 2 Hours).Moreover, students were allowed to use their Arabic English dictionaries in their translation. After that, the data will be analyzed and classified according to some problems of translation.

(2) The students, and after finishing the translation test to the underlined items and phrases, were asked to set for making an interview to talk about the reasons that may stand against creating a close, appropriate, and equivalent renderings. The students were provided with extra papers to write their point of views freely.

\section{Data Collection}

Both qualitative as well as quantitative techniques were used to analyze the data. To analyze the data obtained from the translation test, a quantitative methodology was used. To analyze the participants' point of views concerning the reasons behind such problems from the students' point of views, a qualitative methodology was used.

\section{THE RESULTS AND THEIR DISCUSSION}

\section{Findings Related to the First Research Question}

The first question of the study was: What are the most difficult translation problems that faced the Saudi EFL students in their translation?

To answer the question, means and standard deviations were used to the results of the students in the exam and in the three groups. The following tables 1-3 pointed out the means and the standard deviations for each group separately.

The below tables showed that the cultural terms come in the first rank in its difficulty to the students with a mean of 1.1200 . It is expected for the cultural terms to be a major problem for the students as the two languages are remote culturally. Another reason is that the Saudi students do not have that good knowledge about the western culture so it is normally to be a problem in this study. The results of Mares (2012) Al-Sohbani and Muthanna (2013), Almubarak, Abd.Mannan, and Al-Zubaid (2014), Bakir and Lazim (2015), and Elachachi (2015) supported this point

Table 1. The means and the standard deviations for the students' achievements in the first group

(Lexical problems)

\begin{tabular}{lccc}
\hline \multicolumn{4}{l}{ Descriptive Statistics } \\
\hline & N & Mean & Standard deviation \\
\hline Score & 150 & 1.1400 & 1.18735 \\
Valid N (listwise) & 150 & & \\
\hline
\end{tabular}

Table 2. The means and the standard deviations for the students' achievements in the second group (Cultural problems)

\begin{tabular}{lccc}
\hline Descriptive Statistics & & & \\
\hline & N & Mean & Standard deviation \\
\hline Score & 75 & 1.1200 & 1.89566 \\
Valid N (list wise) & 75 & & \\
\hline
\end{tabular}

Table 3. The means and the standard deviations for the students' achievements in the third group (Terms of address problems)

\begin{tabular}{lccc}
\hline \multicolumn{2}{l}{ Descriptive Statistics } & & \\
\hline Score & N & Mean & Standard deviation \\
Valid N (list wise) & 75 & 4.6933 & 1.11468 \\
\hline
\end{tabular}


of view as culture is really a problem in the process of translation.

As for the lexical problems, they come in the second rank according to their degree of difficulty and with a mean of 1.1400.The lexical items create many problems because of the students' difficulty in finding the appropriate equivalents for the items or the expressions. The reasons behind that could be returned to the lack of vocabulary store, the misunderstanding of the item needed to be translated,and the misusing of the dictionary. This result goes in complete harmony with the results of Al-Sohbani and Muthanna (2013), and Jabak, Abdullah, and Mustapha (2016).

On the other hand, the third group "Terms of address" comes in the third rank in its complexity and difficulty for the students and with a mean of 4.6933. The reason behind such a result may attributed to the simplicity of the five terms of address that students were asked to translate as the majority of them are easy to be rendered. The following analysis supports this result.

\section{Findings Related to the Second Research Question}

The second question of the study was: Which one of the exam's sentences was the most difficult one among the sentences of the three groups?

To answer the question, means and standard deviations were used for the twenty sentences and the results are shown in Table 4.
The table above shows that the most difficult sentence that students faced is sentences number 10 (S10) as it got the lowest mean among the other 10 sentences in the same group as the mean for it was [0.3333] and with a standard deviation of [0.72375].The sentence was: (السلاح تحصل عليه) (ل) الجهاد لا للاغتبال

The reasons behind that may be to the following reasons. The word 《) has a religious connotation. It is more than killing or fighting enemies. Muslims do what we call الجهاديا for religious purposes and not for political purposes or personal interests. From this point, we see that rendering الجهادي" into "fighting the enemy" may be inaccurate. Moreover, we see that rendering 《الاغنيال into "killing" could also be far from the intended meaning. "الاغنيال in Arabic means "assassination" in English. These inappropriate translations by the students and the difference between their meanings may be ascribed to the non-specific renderings of the words

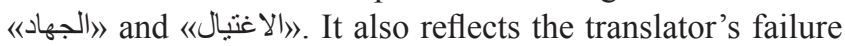
of considering the context of the translated material.

As for the second group, the table shows that sentence number 15 (S15) was the most difficult one as it got the lowest mean [0.1333] and with a standard deviation of [0.51640]. The sentence was (التوكل ترك الايو اء الا الى اله a lowest mean for the this sentence among the other four sentences in the same group, could be referred as this expression is used in the Arab culture in a wide context especially in the religious meetings and ceremonies because it shows a positive agree-

Table 4. The means and the standard deviations for the translation exam's sentences in the three groups

\begin{tabular}{|c|c|c|c|}
\hline The problem & Sentence number & Means & Standard deviations (SD) \\
\hline \multirow{10}{*}{ The Lexical Group } & $\mathrm{S} 1$ & 1.6000 & 1.12122 \\
\hline & $\mathrm{S} 2$ & 1.4667 & 1.06010 \\
\hline & $\mathrm{S} 3$ & 0.9333 & 0.88372 \\
\hline & S4 & 1.4000 & 1.29835 \\
\hline & S5 & 2.0000 & 1.06904 \\
\hline & S6 & 1.1333 & 0.99043 \\
\hline & S7 & 0.0667 & 0.25820 \\
\hline & S8 & 0.8667 & 1.35576 \\
\hline & S9 & 1.6000 & 1.45406 \\
\hline & $\mathrm{S} 10$ & 0.3333 & 0.72375 \\
\hline \multirow{5}{*}{ The Cultural Group } & S11 & 0.8000 & 1.47358 \\
\hline & $\mathrm{S} 12$ & 1.8667 & 2.44560 \\
\hline & S13 & 1.6000 & 2.41424 \\
\hline & S14 & 1.2000 & 1.65616 \\
\hline & S15 & 0.1333 & 0.51640 \\
\hline \multirow{5}{*}{ Terms of Address Group } & S16 & 4.8000 & 1.26491 \\
\hline & S17 & 4.5333 & 0.91548 \\
\hline & $\mathrm{S} 18$ & 5.2000 & 1.01419 \\
\hline & S19 & 4.9333 & 1.27988 \\
\hline & $\mathrm{S} 20$ & 4.0000 & 0.75593 \\
\hline Total of Sentences & 20 & & \\
\hline
\end{tabular}


ment on the fact that Allah has all power to the universe, and we as humans could not do anything except to obey this fact.

As for the third group, the table shows that sentence number 20 (S20) was the difficult one as it got the lowest mean [4.0000] and with a standard deviation of [0.75593]. The sentence was (لوظيفة شيخ المشايخ).The lowest mean for this sentence could be referred as that there are some terms of address that are difficult to be translated into English such as:

(يا مو لانا _ يا حضرة - ياست - معلم القهوة) as it is difficult to find its close and adequate rendering in English because of the cultural differences among the two languages. For these reasons, it is expected that students may fail in rendering this sentence appropriately into English, as it does not have a well-known equivalent in English. Moreover, they differ in meaning according to the social situation among the addresser and the addressee.

\section{Findings Related to the Third Research Question}

The third question was: What are the reasons behind facing such translational problems from the students' point of views? To answer this question, the researcher made interviews for the students and asked them to say their point of views concerning facing such these problems.

After analyzing the students' responses to the third question, five themes emerged; they were:

1. The lack of enough practice in translation.

2. The poor use of using the dictionary.

3. The cultural differences between Arabic and English

4. The limited number of the translation courses in the Department's plan. Only four courses are given to the students in their four years of studying English.

5. The disability in choosing the appropriate meaning to the word that is going to be translated. As the word in Arabic as well as in English may has more than one meaning.

The following table shows the students' responses to the third question providing the number of frequencies as well as the percentage for each theme.

The first theme of "The lack of enough practice in translation" was stated by a few students as it comes in the third rank and with a percentage of $18.51 \%$. This theme reflects the problems that students suffer from as lack of practice results in poor translation. Moreover, the lack of practice may lead to mistranslation to some easy phrases and items because students think inside themselves that they do not have the ability to translate them appropriately.
The theme of "The poor use of using the dictionary" was stated by few numbers of students and with a percentage of $14.82 \%$,where one of them said, "I do not know the quick way in searching for the words that I do not know which takes a lot of time to search for the exact meaning". "Another student said, "I have my own dictionary but I have a lack of practice in searching for the unknown words".

The third theme of "The limited number of the translation courses in the department's plan" was proclaimed by a good number of students, as it comes in the second rank and with a percentage of $25.93 \%$, where one of the participants said, "The department plan consists of limited number of translation courses within the four years of the program". Another student said," We need to study extra translation courses in order to improve our translation practice; at least we need to take eight translation courses through our studying".

The theme of "The cultural differences between Arabic and English" was stated by the majority of the interviewed students. It comes in the first rank and with a percentage of $29.63 \%$. They said that they found many difficulties while rendering from English into Arabic and vice versa. They agreed that the cultural differences between the two languages cause many translation problems.

As for the "The disability in choosing the appropriate meaning to the word" theme, only three of the interviewed students said that we find a lot of difficulty in choosing the needed meaning to the difficult words, that they face while rendering from one text to another, as the word in the dictionary has many meanings. They said that some words have more than five meanings to the same word. The result of this question is supported by Al-Sohbani and Muthanna (2013), and Jabak, Abdullah, and Mustapha (2016).

\section{CONCLUSION AND RECOMMENDATIONS}

The purpose of the current study was to investigate the most common translation problems that encountered the Saudi EFL students in translating some of the literary items from Arabic into English due to cultural, lexical, and terms of address difficulties. Moreover, it aimed to explore the students' point of views concerning the reasons behind facing such these difficulties in the process of translation. Besides, it tried to explore the most difficult sentences that faced the students in the process of translation. The findings of the study showed that the students' achievement in translating the items of the terms of address was the best compared with their results in the other two groups (lexical and cultural).

Table 5. The themes and their number of frequencies and percentage

\begin{tabular}{lcc}
\hline The theme & Number of frequencies & Percentage \\
\hline 1. The lack of enough practice in translation. & 5 & 18.51 \\
2. The poor use of using the dictionary. & 4 & 14.82 \\
3. The cultural differences between Arabic and English & 8 & 29.63 \\
4. The limited number of the translation courses in the Department's plan. & 7 & 25.93 \\
5-The disability in choosing the appropriate meaning to the word. & 3 & 11.11 \\
Total & 27 & 100 \\
\hline
\end{tabular}


Moreover, the analysis of the students' interviews indicated that the lack of practice and lack of translation courses are main reasons in facing such these problems. Besides, the analysis of the students' interviews indicated that the lack of practice and lack of translation courses are main reasons in facing such these problems. Moreover, the results presented some of the most difficult sentences that the students encountered while translating them as some of them have religious connotations.

Based on the results of the study, the present study recommends the following: Firstly, the researcher sees that the translator, in addition to having good command of SL and TL languages, should also be aware of the two cultures. In other words, he should be sensitive to religious and social terms as having a good knowledge between the differences of the two cultures will definitely facilitate the process of translation.

Secondly $\mathrm{He} / \mathrm{she}$ should be faithful to SL text providing as he must do his best to produce a close, appropriate, and equivalent TL text. In adopting this strategy, his/her translation looks natural.

Thirdly, the translator should have a good knowledge about the relevant of the terms of address in the two languages as that might be functional and highly flavored terms of address in one language may be turned to be flat in another language. Hence, utmost care should be given to these terms of address in both languages to give them their close and natural equivalent.

Moreover, university translation courses must be increased for the students as four translation courses are not enough to provide the students with the good practice and knowledge to deal with different literary texts, as the current situation of the students, who participated in this study, is unsatisfactory.

In addition, lecturers as well as professors who teach translation courses for the students in the Saudi universities should explain the best way of using the dictionaries correctly a lot of concern as a good number of the students said that their poor use of the dictionaries stands against their development in the translation courses.

Finally, it is advisable for all translation lecturers to start their courses at the beginning of each academic semester with exercises on how to use the dictionaries appropriately as well as the suitable way to choose the intended meaning in the SL text according to its context.

\section{REFERENCES}

Al-Kuteifan, H. (1995). Intertextuality in the Translation of Political newspapers headlines from Arabic into English. Unpublished Thesis, Yarmouk University, Irbid.
Almubark,A., Manan,A., \& Al-Zubaid, K. (2014).The Hindrances in Translating Specific Cultural from Arabic into English.Journal of Humanities and Social Science, 19(3),166-173.

Al-Sohbani,Y., and Muthanna, A.(2013).Challenges of Arabic-English Translation: The Need for Pre-Systematic Curriculum and Methodology Reforms in Yemen. Academic Research International. 4(4),442-450.

Bakir, K., and Lazim, H.(2015).Stylistic Problems Confronting Arab Students in Arabic-English Translation. Retrieved 20 January, 2018

From http://www.translationdirectory.com/articles/article1333.php

Catford, J. (1965). A Linguistic Theory of Translation: An Essay in Applied Linguistics. London: Oxford University Press.

Crystal, D. (1992). Language and Languages. London: Blackwell Publishers.

Dweik, B. \&Abu Helwah, W. (2014). Translating historical and religious Texts from Arabic into English: Problems and Solutions. Hebron University Research Journal (A), 9(1), 285-303.

Elachachi,H.(2015).Exploring Cultural Barriers in EFL Arab Learners' Writing. Procedia - Social and Behavioral Sciences, 199(3), 129-136.

Enkvist, N., Spencer, J., \&Gregory, M. (1978). Linguistic and Style.London: Oxford University Press.

Ghazal,H.(2008).Translation as Problems and Solutions. Retrieved 25 January, 2018 from https://drive.uqu.edu. sa/_ofahmawii/files/Translation\%202-ilovepdf- compressed.pdf

Hartman, K. and Stork, F. (1972). A Dictionary of Language and Linguistics. London: Applied Science Publishers LTD.

Jabak, O., Abdullah, S., \&Mustapha, N.(2016). The Difficulty of Translating Collocations from Arabic into English Encountered by a Sample of Arab Students. Retrieved 24 January, $2018 \mathrm{http}: / /$ journal.kuis.edu.my/jsass/images/files4b/4_025-Omar.pdf

Mares, R. (2012).Cultural Difficulties in Translations from English into Arabic. Retrieved 18 January,2018,https:// www.europeana.eu/portal/en/record/9200419/Bibliographic Resource

Neubert, A.,\& Shreve, G. (1992). Translation as a Text. Ohio/London: The Kent State University Press.

Tahaineh,Y., \&Tafish, R. (2011).Pitfalls Encountered by bilingual Arab Learners in Translating the Arabic Discourse Marker "Oumma" into English. Theory and Practice in Language Studies.1(3),226-238.

Waard,J.\&Nida,E.(1986).From One Language to Another: Functional Equivalence in Bible Translating. Nashville: Nelson. 


\section{ARABIC REFERENCES}

$$
\text { محفوظ، نجيب. اللص والكلاب. (دار القلم: بيروت،1973). }
$$

\section{Appendix (A)}

Note: Translate the underlined phrases from Arabic into English.

*ترجم ما تحته خط إلى الإنجليزية:-

\section{1-LEXICAL PROBLEMS}

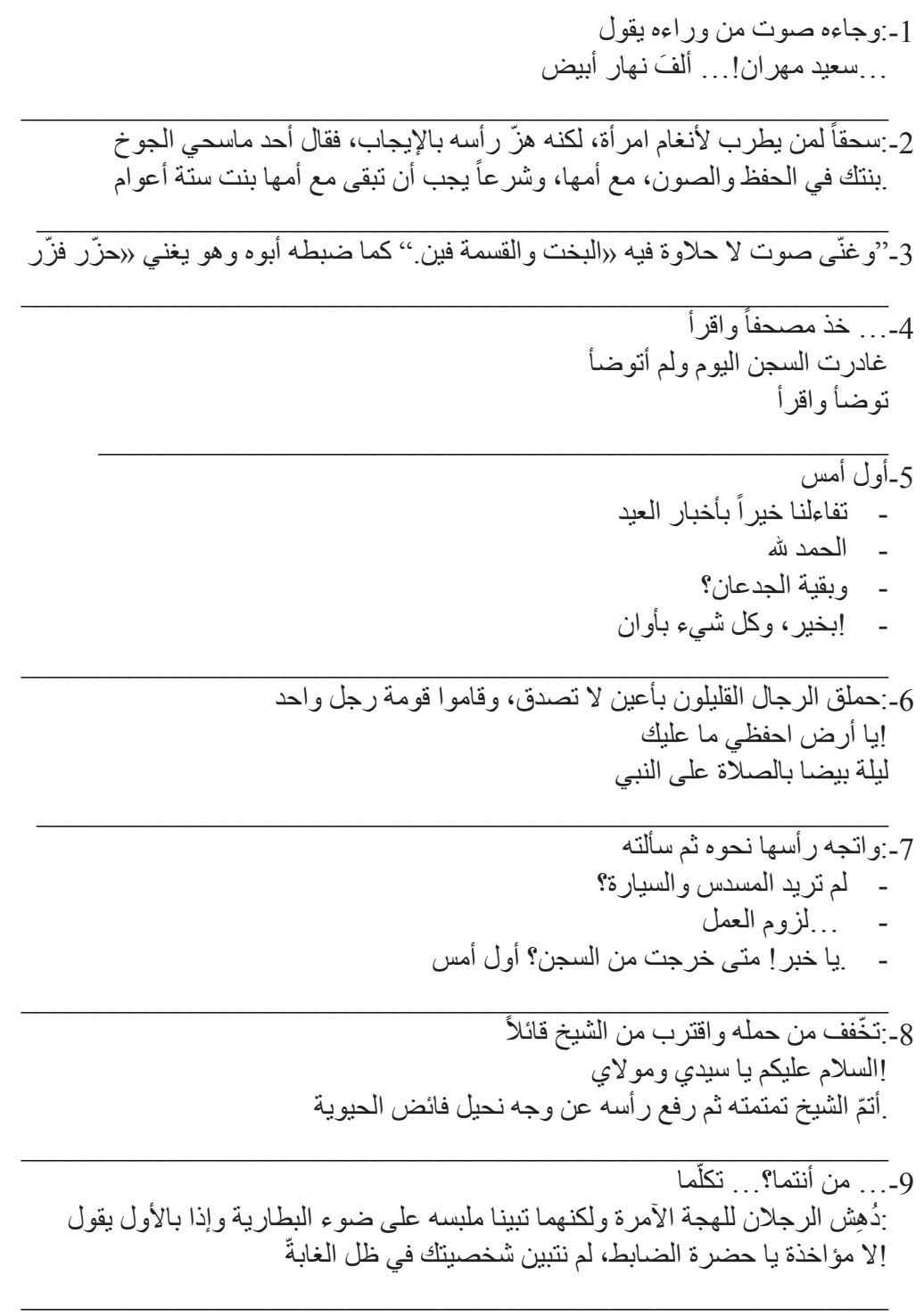

10-10 السلاح تحصل عليه للجهاد لا للاغتيال

\section{2-CULTURAL PROBLEMS}

11-.فالتفت ور اءه فر أى المعلم طرزان مادًا يده الأخرى بالمسدس وهو يقول: نار على عدوك بإذن الله 12-.فقالت أنا يتيمة وليس لي إلّّ عمة بسيدي الأربعين، فقلت على بركة الله وقبلّتها أمام الهلال، و الفرح من جماله عاش أحدوثة على كل لسان 13-13:وسر عانٍ ما هر عت إليه حتى تلاقت الأيدي وهي تقول

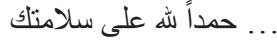




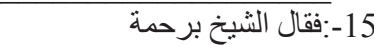

التوكل ترك الإيواء إلاّا إلى الله.

\section{3-TERMS OF ADDRESS PROBLEMS}

16-وـ انحدر اليهم صبي القهوة حاملا نارجيلة تتو هج جمر اتها ويتطاير منها الشرر مطقطقا

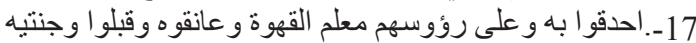

18- أشكرك يا معلم بياظة

19 ياست نور

20 لوظيفة شيخ المشايخ 